\title{
Sobre la aplicabilidad de teorías "poscoloniales" a las culturas centroeuropea y latinoamericana
}

Michael Roessner

En la última década del siglo XX, las teorías poscoloniales se han puesto de moda. Como la -hasta ahora- última novedad en el campo "post" de la posmodernidad se han desarrollado de un campo relativamente estrecho de intereses (se hablaba en un primer momento exclusivamente de la situación particular de las ex colonias británicas en África y Asia) hacia una teoría que después de liberarse del logocentrismo y del falogocentrismo (con los posestructuralistas y los gender studies) llegaría a liberarse del "euro-falogocentrismo" para abrirse a una visión policéntrica (o a una que por lo menos toma en cuenta la relación centro-periferia en sus reflexiones) de la cultura. En el campo de la literatura, se trata por supuesto en primer lugar de relaciones de comunicación -y con esto también de poder.

Me permitiré sintetizar en pocas palabras lo que me parece importante de esta escuela para desarrollar después los pros y contras de la aplicación de algunos conceptos a la cultura latinoamericana $y$, basado en esta experiencia, a posibilidades de transferencia de tal perspectiva a la cultura centroeuropea.

\section{Las teorías poscoloniales}

Empezamos con el breve cuadro de la teoría: el núcleo más importante de los teóricos de post-colonial studies se compone de Edward 
Said, Homi Bhabha y Gayatri Spivak -tres personas con sorprendentes paralelos en sus biografías: los tres son originarios de ex colonias británicas situadas en el "Oriente", crecieron en un contexto anglófilo, estudiaron en universidades de elite británicas o norteamericanas y eran (o son) catedráticos en tales universidades de elite en Estados Unidos; ${ }^{1}$ desde allí, sus teorías -si queremos aplicar por un momento su contenido a ellos mismos- ocupan de manera privilegiada canales de comunicación que desde el centro llegan a la periferia (que en este sentido nos comprende a todos, latinoamericanos como europeos).

Originariamente, los post-colonial studies fueron concebidos exclusivamente para un determinado imperio, el británico. Homi Bhabha, uno de los representantes más conocidos de esta escuela, dijo hace algún tiempo, en nuestro seminario de posgrado en Múnich, que le impresionaba siempre que las teorías que él y sus colegas habían desarrollado para un sector muy concreto y limitado podían ser aplicadas a situaciones tan variadas -y lo dijo con la mezcla tan británica de admiración e ironía. Por supuesto que tampoco y no sin coquetería: los post-colonial studies, difundidos de la manera semicolonial descrita, forman hoy en día en todo el mundo una parte esencial de la base teórica de las ciencias culturales.

Cronológicamente, el primero de los tres mayores representantes fue el palestino Edward Said con su ensayo Orientalism (1977). El mérito de este libro fue el de desarrollar un problema de base de la etnología tradicional (que ya mucho antes se manifiesta por ejemplo en la obra del etnólogo-surrealista Michel Leiris) hacia el contexto de una crítica generalizada de las bases de la ciencia occidental. El pensamiento occidental como base de la identidad europea-occidental, según Said, tiene su fundamento en una oposición: para la definición

${ }^{1}$ Edward Said, fallecido en 2003, fue profesor de la Columbia University; Homi Bhabha está en Harvard; y Gayatri Spivak, en la Columbia. 
de lo propio era necesario lo otro, y por esto se habría inventado este otro en forma del llamado "Oriente", al mismo tiempo forzando con el poder del Centro al Oriente a comportarse de tal manera que correspondía a las expectativas del Centro. En este contexto Said habla de una "actitud textual" y pretende que los textos occidentales sobre el Oriente analizados por él tenían la capacidad de "crear no sólo un conocimiento, sino también la realidad que parece[n] describir. Con el tiempo, este conocimiento y esta realidad dan lugar a una tradición, o a lo que Michel Foucault llama un discurso" (Edward Said, 124). Así, el discurso sería una especie de cárcel virtual creado por la "voluntad de poder" de Occidente en relación con Oriente que fuerza al oriental a desempeñar un papel determinado en el que será lo otro, la sombra de la identidad occidental.

Esta teoría seduce por la claridad de la expresión y del esquema bipolar; sin embargo, me parece ser un poco superficial. Primero, no distingue entre varias partes o regiones de Oriente (desde el imperio turco hasta Japón, sin mencionar a los países africanos e incluso latinoamericanos que en cierta manera, parece, habría que definir también como parte del oriente saidiano, dado que hay sólo Occidente-Centro y Oriente-Otro).

Segundo (y más grave), concibe la comunicación cultural en una situación colonial y poscolonial como unidireccional: la "pureza" del Centro no sufriría en absoluto a través del contacto con lo otro, al contrario, por la creación de este otro se establecería de manera definitiva.

Homi Bhabha, indiano de nacimiento y profesor en Estados Unidos como Said, escapa a tales objeciones por su teoría fundamental de la hibridización. Incluso la comunicación bajo las peores condiciones de represión colonial para él nunca es unidireccional, sino que siempre lleva a una hibridización que a su vez implica una "subversión” de la autoridad colonial: 
If the effect of colonial power is seen to be the production of hybridization rather than the noisy command of colonialist authority or the silent repression of native traditions, then an important change of perspective occurs. The ambivalence at the source of traditional discourses on authority enables a form of subversion, founded on the undecidability that turns the discursive conditions of dominance into the grounds of intervention ("Signs Taken for Wonders" en The Location of Culture, Nueva York, 1994: 112).

De esta concepción fundamental de intercambio cultural resulta para Bhabha necesariamente toda una serie de conclusiones que llevan a conceptos como "liminality", "third space", o el "In-Between" excluyendo de esta manera ideas tradicionales de "pureza" o "autenticidad" de culturas. Por supuesto, esta teoría permite también relacionarse directamente con las tesis de los "clásicos" de las teorías de posmodernidad y posestructuralismo (desde Lacan y Derrida hasta Deleuze y Guattari), y asimismo con Bajtin que es de enorme importancia para las teorías de Bhabha.

El mismo Derrida es también el punto de partida para Gayatri Chakravorti Spivak que -dentro de la concepción general de Bhabha- subraya una distinción de culturas dominantes y "subalternas" dentro de la cultura periférica. Los llamados "subalternos", que en el proceso de comunicación no sólo están desventajados por su posición periférica, sino además de una o varias características (por ser mujeres, homosexuales, pertenecer a etnias o clases sociales marginadas, etc.) por principio no tienen voz propia, participan en la comunicación sólo pasivamente, es decir, padeciéndola y no haciéndola, si no se encuentra nadie que les presta su voz a ellos -y por supuesto, es la misma Spivak, autora del famoso ensayo Can the Subaltern speak? que se ofrece como "voz prestada" para los subalternos- con todas las implicaciones problemáticas de tal actitud.

Con esta "trinidad poscolonial" nos hemos quedado únicamente en el campo anglosajón, y es verdad que esta post-colonial theory en 
un primer momento fue producto de las "nuevas literaturas anglófonas" creadas en el campo de la filología inglesa, y por eso está hasta hoy en día dominada -como ya dijimos antes- por la situación de las ex colonias británicas, es decir, por países en África o Asia cuya colonización se llevó a cabo entre fines del siglo XVIII y el XIX, y era una colonización predominantemente económica y no demográfica -casi no hubo inmigración, y donde la hubo, como en el caso de África del Sur, se realizó sólo en combinación con una política muy fuerte de separación racial entre indígenas e inmigrantes. La situación de las colonias francesas es diferente, para no hablar de otras regiones del mundo. Para América Latina finalmente, el debate sobre la legitimidad o ilegitimidad del empleo del término "poscolonial" hasta ahora resulta muy polémico y controvertido.

En la versión más sencilla de la argumentación, el concepto no se acepta simplemente por el hecho de que en América Latina no ha habido nunca una descolonialización verdadera, ya que fueron los criollos quienes lucharon por la independencia de los países latinoamericanos, no los indígenas "colonializados", que muchas veces padecieron peor represión en las nuevas repúblicas independientes que anteriormente y que hasta hoy en día (si han sobrevivido) desempeñan un papel marginado en las sociedades latinoamericanas, son una "periferia de la periferia" (Lienhard en De Toro, 1999). Jorge Klor de Alva decreta por lo tanto de forma muy clara: [...] "where there was no decolonization there could be no postcolonialism, and where in a postindependance society no postcolonialism can be found, the presence of a preexisting colonialism should be put in question" (1992: 4).

Esta tesis por supuesto tiene mucho de verdad: el primer siglo de la independencia de los países latinoamericanos es caracterizado por la dominación de por lo menos dos "imperios coloniales secretos": en el campo cultural, el centro es Francia; en el tecnológico-económico, 
Inglaterra; en México ya bastante temprano, en el resto del subcontinente a partir del fin de siglo XIX se hace sentir el poder de un tercer imperio que mantiene su posición dominante hasta hoy en día: los Estados Unidos.

También en cuanto a la relación que mantienen las sociedades latinoamericanas en lo que se refiere a su tradición cultural indígena y a la construcción de una nueva identidad cultural propia, durante mucho tiempo se mantiene un vínculo casi colonial con Europa; baste citar un ejemplo, el del premio Nobel guatemalteco Miguel Ángel Asturias, él mismo mestizo con sangre maya quien en su tesis doctoral decreta que los indios "como cada raza animal en extinción" no pueden ser salvados sino por un "cruce con razas sanas" como "bávaros, holandeses o tiroleses", y proclama que deben olvidar su propia lengua y ser aculturados únicamente en castellano. Después llega a la Sorbona y descubre allí y en los cafés de los surrealistas el interés europeo en las formas de pensar exóticas de los indígenas, participa en la traducción del Popol Vuh (de la versión francesa de su maestro parisiense Georges Raynaud) y así crea un lenguaje en castellano capaz de captar esta forma de pensar. En Leyendas de Guatemala y en su novela Hombres de maiz, este lenguaje y esta perspectiva le ayudan a lograr innovaciones estéticas fundamentales para la nueva novela latinoamericana, y se presenta en los años cincuenta en Europa como el "Gran lengua de los maya y voz de mi tribu", a pesar de no hablar ni una palabra de alguna lengua indígena.

Esto no puede quitarle el mérito de haber creado una innovación lingüística y narratológica de primordial importancia para la creación de una nueva técnica y un nuevo lenguaje literarios en este continente. Lo único que hay que confesar es que estas innovaciones serían inconcebibles sin los impulsos de la vanguardia y la ciencia europeas -y por el otro lado sin la demanda "exotista" del mercado europeo que permitió el establecimiento de la "literatura de exporta- 
ción" (Pau-Brasil) como la literatura más importante del mundo en época del boom-, sin embargo, es siempre un ejemplo de "economía colonial", porque el material bruto (la "creación") llega de América Latina, la transformación y las ventas a nivel internacional (la crítica, los agentes literarios, las grandes editoriales) están en Europa o en los Estados Unidos.

Por otro lado, se podría también decir que en Latinoamérica encontramos un pensamiento en "categorías poscoloniales" ya mucho antes de la independencia. Sara Castro Klarén (en De Toro, 1999: 137-164) quiere hallar el inicio de tales categorías en la obra del Inca Garcilaso de la Vega, hijo de un conquistador de la nobleza española $\mathrm{y}$ de una princesa real indígena. El Inca realiza en sus Comentarios reales del inicio del siglo XVII por un lado la "diáspora" característica que encontramos en las teorías de Bhabha (escribe en Andalucía y para lectores españoles en un estilo petrarquista impecable, código de la "internacional humanista" de aquel entonces), por el otro está subvirtiendo los conceptos centro-periferia al definirse como "ciudadano de Cuzco, es la otra Roma en aquel continente”. Eso siempre -según Castro Klarén- corresponde exactamente a la definición bhabhiana del "post-colonial intelectual", así que se puede afirmar que América Latina no es tan sólo "post-colonial avant la lettre" (Casullo, 1991), sino incluso "post-colonial before the 'post" (Castro Klarén en De Toro, 1999: 146). No se puede negar que el Inca Garcilaso aparece como un representante de la "travelling culture" en una época en que los países modelo de los post-colonial studies no eran ni siquiera colonizados. Las bases de su escritura son europeas, pero precisamente por eso desarrolla una teoría de dos mundos paralelos: además de la primera Roma en Europa, de la que deriva la translatio imperii y con ésta el fundamento de derecho de todo poder estatal y espiritual en Occidente, existe otra segunda Roma en América, y con ella un segundo ombligo (Cuzco) de la historia mundial; por las uniones, 
como aquella de sus padres, estas dos historias mundiales paralelas confluirán finalmente en una, que tienen la misma dignidad. Esto me parece un buen ejemplo de la subversión de la comunicación cultural por la periferia a pesar de la posición dominante del centro europeo.

Otra variante de una actitud poscolonial en la época colonial la podríamos encontrar en la obra del petrarquista boliviano Diego Dávalos y Figueroa, quien desde su huerta aislada en el altiplano boliviano trata de participar directamente en la discusión sobre la lengua literaria que hay que utilizar en el centro humanista por excelencia, Italia (la famosa "Questione della lingua") -con esto salta por encima de los "centros intermedios" como Lima, ciudad de México y Madrid, en una tentativa casi absurda de salir del aislamiento periférico y de utilizar el impulso de la naturaleza indómita y de la necesidad de sustituir lo que le falta para llegar a innovaciones en el petrarquismo internacional.

Una tercera -y más radical- variante sería aquella del peruano Waman Puma de Ayala que combina las tradiciones del sermón barroco con la comunicación pictórica de las culturas andinas en su larga obra Nueva corónica y buen gobierno, que en parte se presenta como una carta dirigida al rey español con muchos diseños que enumera los problemas del mal gobierno, cuenta la historia preincaica, incaica y colonial (desde la Génesis bíblica), describe a los varios oficios de la sociedad virreinal, etc., todo ello con textos parcialmente en un español nada perfecto, parcialmente en quechua.

En todas estas variantes encontramos una especie de "tercer espacio" entre las culturas indígenas y/o por lo menos extra europeas y el centro europeo -que en el caso concreto del siglo XVI es precisamente Italia-. De esto resulta una confusión entre centros y culturas periféricas: lo que en una relación es el centro (por ejempo, la corte de Madrid para las cortes virreinales), en otra relación (el humanismo internacional) se revela cultura periférica que se puede pasar por alto 
para entrar en un diálogo directo con el "centro superior", como lo demuestran tanto el caso de Dávalos como la tentativa de Waman Puma de presentarle al emperador el borrador de un nuevo orden mundial basado, en parte, en principios europeos, en parte en principios indígenas, redactado en parte en un español deficiente, en parte en imágenes.

Y si se me contesta que Waman Puma era un personaje marginado cuya carta nunca llegó a su destinatario, se podría citar el caso de un personaje mucho más conocido que, según Castro Klarén, representaría el primer y único "europeo poscolonial": fray Bartolomé de las Casas. Se puede dudar de que sea de veras un ser poscolonial, pero no se puede dudar de su condición nada marginada, porque De las Casas tenía una posición central de poder en la corte y lograba imponer la introducción de las Leyes de Indias.

Podríamos ahora seguir cronológicamente y buscar intentos de tal relativización de la relación comunicativa entre centro y periferia en la literatura de la Independencia, en el modernismo y en las vanguardias, en la literatura del boom y finalmente en el posmodernismo latinoamericano -en última instancia, el resultado sería, creo yo, la frase que el joven Borges escribe ya en 1932 (en "El escritor argentino y la tradición") ${ }^{2}$ y que se deja aplicar al continente entero: que los latinoamericanos -como los judíos- tienen el derecho de no sólo ocuparse de lo propio sino de apropiarse de la totalidad de la tradición cultural europea, a diferencia de los europeos que siempre estarán ligados a una tradición nacional aislada. Esto les ofrecería también la posibilidad de crear hibridizaciones inalcanzables para los mismos europeos, lo que podría clasificarse en la época de la paulatina unificación europea incluso como una "ayuda al desarrollo" prestada por América Latina a la antigua metrópolis europea.

${ }^{2}$ En Prosa completa, 1980, Bruguera, Barcelona, pp. 215-223. 


\section{Las teorías latinoamericanas: poscolonialidad, descentramiento y dialogicidad}

Finalmente hay que tener en cuenta también la tradición del pensamiento teórico latinoamericano que incluso si acepta en general elementos de las teorías poscoloniales no se contenta con una orientación exclusiva en la trinidad Said-Bhabha-Spivak; así, investigadores como Walter Mignolo en los Estados Unidos reclaman la prioridad de pensadores latinoamericanos como O'Gorman y Ángel Rama que ya antes de Said \& Co. habrían dudado, basándose en teorías de Heidegger, de la validez absoluta de la lógica occidental. Walter Mignolo encuentra un nuevo concepto que puede oponerse a lo poscolonial: el "posoccidentalismo". Así se puede oponer un autor que subvierte perspectivas coloniales con base en el conocimiento y pensamiento europeos como Carlos Fuentes (definido como "poscolonialista") a un autor como Juan Rulfo que sencillamente en su práctica de escribir se libera de la hegemonía del pensamiento eurocéntrico (definido como "posoccidentalista") (Alcántara Mejía en De Toro, 1999).

Si nos preguntamos cómo habría que definir tal escritura posoccidental, llegamos finalmente a algunas ideas originales e innovadoras de la teoría latinoamericana que Alfonso de Toro define también como características de una "poscolonialidad" opuesta a poscolonialismo. Quiero mencionar brevemente sólo tres de ellas:

1) El concepto de "heterogeneidad" de las culturas latinoamericanas desarrollado por el sociólogo de la cultura José Joaquín Brunner (Chile). Brunner niega el mito de la pérdida de la "identidad y pureza originarias" y presenta la cultura latinoamericana con la imagen del espejo rajado o quebrado que refleja un conjunto caótico de variadas facetas de alta cultura y cultura popular, cultura de masas y folclore sin que exista concepto ordenador alguno que permitiría agruparlas según una dirección de progreso o una meta. 
2) El concepto de Jesús Martín Barbero, español de nacimiento y colombiano de adopción, que trata de analizar de manera parecida la formación de identidades a través de una tendencia "destotalizadora", en vez de una "identidad" nacional o continental. Prevé una tensión activa entre lo histórico y el presente en un "tercer espacio", un "intersticio" que debería efectuar una "desterritorialización" de lo autóctono-popular periférico y la consiguiente "reterritorialización" en el centro.

3) El concepto de la hibridización de Néstor García Canclini (1991) que parte del concepto de una interacción dinámica entre "cultura de masas, cultura popular y cultura de elite", entre "elementos locales y elementos cosmopolitas".

En el contexto académico alemán, mi colega Alfonso de Toro ha tratado de combinar tales conceptos con los teoremas posestructuralistas, sobre todo aquellos de Derrida y de Deleuze-Guattari: según él, estos conceptos latinoamericanos (que él llama expresamente "poscoloniales") mostrarían la estructura del pensamiento "rizomático" según Deleuze y Guattari, una estructura que ya no se prestaría a oposiciones estáticas entre lo propio y lo otro, sino a un dinamismo que De Toro expresa en el concepto de "altaridad" en vez de "alteridad" - un concepto desarrollado por Taylor paralelamente a la "différance" de Derrida.

No importa si queremos seguir esta proliferación de conceptos nuevos o no: lo que me parece importante es la intención de superar así la vieja bipolaridad centro-periferia, hegemonía-dependencia, etc., y llegar a lo que De Toro llama "dependencia y contaminación recíprocas" de periferia y centro, a un "descentramiento y una multiplicación del centro". Así De Toro -que ve la posición de América Latina como aquella de una "posmodernidad periférica poscolonial" -define esta "poscolonialidad" (a diferencia del poscolonialismo) como sigue: "un discurso que busca un espacio de la dialogicidad 
que existe como potencialidad" y para el que la "globalización ofrece nuevas posibilidades".

Podemos discutir el pro y el contra de tal conclusión audaz; el hecho de relativizar la relación centro-periferia en el sentido de la "metaforización" que hemos mencionado me parece en todo caso una idea válida que resulta de la situación específica latinoamericana pero que se podría aplicar también a otras culturas - para corregir una perspectiva demasiado simplista bipolar del poscolonialismo.

Tal definición permitiría incluso una aplicación de estas formas de poner preguntas y estos conceptos en una forma adaptada (tal vez incluso sin nombrar más la etiqueta muy vaga de "poscolonial") a situaciones culturales que no resultan directamente de situaciones coloniales como aquella de Europa central. En un coloquio de la Academia Austriaca de Ciencias sobre eventuales aspectos poscoloniales en la cultura del antiguo Imperio Austro-Húngaro he propuesto trabajar con estos conceptos y paralelismos en varios sectores:

1) Los sectores de contacto entre las varias capas jerarquizadas de la cultura. Con nuestros estudios acerca de la literatura de los cafés (Michael Roessner, 1999) que agrupan tanto Centroeuropa como América Latina, hemos dado un primer paso, ya que la literatura de los cafés durante mucho tiempo fue considerada como literatura "menor" y sin mucho valor, pero representó la base del cambio radical en la cultura que representan las vanguardias. Sin embargo, creo que también otros sectores (por ejemplo la música y el teatro musical, Strauss y la música "seria”; el drama "popular" de Nestroy al teatro del bulevar, etc.) podrían ser de interés para tales investigaciones. También en este campo son impresionantes las semejanzas que se encuentran entre la cultura centroeuropea y aquella de algunos países latinoamericanos como Argentina y Uruguay, donde alrededor del 1900 el teatro moderno [re-] nace del circo criollo (!) y de la revista del sainete musical, que lleva 
hasta un estilo propio del teatro "serio" (el "grotesco criollo" de Armando Discépolo y otros) y donde el tango-canción se asocia de forma tan estrecha con la literatura que algunos de los más importantes poetas tangueros (como Enrique Santos Discépolo) se cuentan también entre los poetas líricos más importantes de su época.

2) El descentramiento o el policentrismo que -como hemos mostrado- es ya característico de la literatura latinoamericana más temprana, se encuentra también en el imperio austriaco, reforzado aún por la multiplicidad lingüística. Para todas las etnias que no viven en su totalidad dentro del Imperio existen necesariamente centros externos que pueden servir de modelo (Berlín, Florencia, Venecia, Roma, etc.), pero también para los otros el centro no es únicamente Viena, Budapest o Praga o (según el concepto del paneslavismo) San Petersburgo, sino - por ejemplo para la literatura y la pintura- también París (para mencionar un solo ejemplo: en 1909, el joven Lajos Kassák camina de Budapest a París para fundar más tarde en 1915 con el "activismo" húngaro el primer grupo de vanguardia en territorio del imperio de los Habsburgo, y para las vanguardias checas, croatas y eslovenas se puede verificar la misma orientación).

Por otro lado, incluso dentro de los países del Imperio AustroHúngaro vemos una confusión de los papeles de centro y periferia parecida a la latinoamericana. Por ejemplo, si Buenos Aires es periférico en relación con París, es centro absoluto en relación con la capital paraguaya, y las relaciones entre Viena y Praga, Viena y Brunn o Viena y Czernowitz son todavía más complicadas por la interferencia entre las culturas judía, checa, alemana, polaca y ucraniana. Para estudiar esta situación, habría que analizar en detalle los canales de comunicación cultural y las posiciones de poder relativas, pero también el efecto fértil "rumorosidad" ("noise", "Rauschen") y de la "contami- 
nación" (en sentido metafórico) de los mensajes, así como aquella del feed-back que hace que cada periferia tenga a su vez influencias que realizan su efecto en su centro relativo. Probablemente no será nunca posible diseñar un mapa exacto de estas influencias recíprocas, pero sí tal vez un "mapa" en el sentido de Deleuze y Guattari, ${ }^{3}$ es decir, una especie de acercamiento dinámico al potencial creativo producido por esta constelación y que sigue produciendo efectos.

Tal flexibilización del empleo de los conceptos como se produjo en América Latina podría permitir la aplicación de muchas ideas y teorías poscoloniales a las culturas centroeuropeas. Esto no vale sólo para la teoría de la cultura, sino también para contextos políticoeconómicos -por ejemplo, el papel "relativo" de centro político que corresponde a Viena y Budapest en relación con los croatas. La situación se vuelve todavía más compleja - pero también más fascinantesi ampliamos la perspectiva en ambos planos: hacia una orientación en centros culturales y/o económico-tecnológicos fuera del imperio austriaco (Berlín-París-Londres) que tenían una posición de modelo incluso para la población "no germanófila". Y en la otra dirección incluyendo el fenómeno denominado "microcolonialismo" que convierte a la ciudad periférica en centro de sus alrededores, a la nación "histórica" en "colonizador" de la nación "no histórica", etcétera.

El siglo XX ha tratado de impedir, de eliminar, de cubrir hasta el último momento tal "descentramiento y multiplicación del centro". Incluso las naciones "tardías" que lograron su propio Estado sólo a fines del siglo pasado -para inmediatamente pedir la entrada en la Unión Europea- quieren todavía crear su propio "patrimonio cultural" siguiendo los modelos del siglo XIX e inicio del XX como “cultura nacional pura”. Tal vez sea más fácil para las naciones latinoamericanas que, con excepción de Brasil, tienen la misma lengua y

${ }^{3}$ Cfr. Gilles Deleuze y Félix Guattari, Anti-CEdipe y Rhizome. Introduction. 
viven tan cerca del nuevo súper centro global Estados Unidos reconocer que su verdadera identidad podría hallarse precisamente en esta hibridez, en este cruce de discursos de una realidad influenciada por la cultura cotidiana de Estados Unidos y no obstante "contaminada por lo local”. Para la Europa que se está uniendo sería, a mi parecer, un paso muy importante y positivo orientarse menos hacia una Europa de las Naciones que hacia una imagen de un continente que lleva en su patrimonio cultural por lo menos tantas culturas híbridas, más "impuras" que puras, y cuya historia desde siempre $-y$ muy en particular en la Europa central- solía comprender "un espacio de la dialogicidad que existe como potencialidad”.

\section{Bibliografía}

Casullo, Nicolás (ed.), 1991, El debate modernidad-posmodernidad, El Cielo por Asalto, Buenos Aires.

García Canclini, Néstor, 1990, Culturas hibridas. Estrategias para entrar y salir de la modernidad, Paidós, México.

Herlinghaus, Hermann y Utz Riese (eds.), 1997, Sprünge im Spiegel. Postkoloniale Aporien der Moderne in beiden Amerika, Bouvier, Bonn.

y Monika Walter (eds.), 1994, Posmodernidad en la periferia. Enfoques latinoamericanos de la nueva teoría cultural, Langer, Berlín.

Klor de Alva, Jorge, 1992, "Colonialism and Postcolonialism as (Latin) American Mirages" en Colonial Latin American Review, núm. 1, pp. 3-23.

Lienhard, Martin, 1992, "Kulturelle Heterogenität und Literatur in Lateinamerika" en Iberoamericana 3-4, pp. 95-110.

Martín Barbero, Jesús, 1993, Communication, Culture, and Hegemony. From the Media to Mediations, Sage / Londres / Newbury Park / Nueva Delhi.

Mignolo, Walter, 1995, The Darker Side of Renaissance. Literacy, Territoriality, \& Colonization, The University of Michigan, Ann Arbor.

Rabasa, José, 1993, Inventing America: Spanish Historiography and the Formation of Eurocentrism, Londres, Norman.

Rama, Ángel, 1984, La ciudad letrada, Ediciones del Norte, Hanover. 
Richard, Nelly, 1989, La estratificación de los márgenes, Francisco Zegers, Santiago de Chile.

Rincón, Carlos, 1995, La no simultaneidad de lo simultáneo. Posmodernidad, globalización y culturas en Latinoamérica, Universidad Nacional, Bogotá.

Rössner, Michael,1988, Auf der Suche nach dem verlorenen Paradies. Zum mythischen Bewußtsein in der Literatur des 20. Jahrhunderts, Athenäum, (Monografien Literaturwissenschaft, vol. 88), Fráncfort d.M.

, 1991, "Fernando del Paso: realismo loco o lo real maravilloso europeo" en Kohut, Karl (ed.), Literatura mexicana hoy, Vervuert, Fráncfort d.M., pp. 223-229.

,(ed.), 1999, Literarisch Kaffehäuser-Kaffehausliteraten, Böhlau, Viena / Graz / Colonia.

,(ed.), 2002, Lateinamerikanische Literaturgeschichte, Metzler, Stuttgart.

Scharlau, Birgit (ed.), 1994, Lateinamerika denken. Kulturtheoretische Grenzgänge zwischen Moderne und Postmoderne, Narr, Tubinga.

, 1990, Said Edward, Orientalismo, Libertarias, Madrid.

Seed, Patricia, 1991, "Colonial and Postcolonial Discourses" en Latin American Research Review, 26/3, pp. 181-200.

, 1993, "More Colonial and Postcolonial Discourses" en Latin American Research Review, 28/3, pp. 146-152.

Toro, Alfonso de (ed.), 1995, Borders and Margins: Post-Colonialism and Post-Modernism, Vervuert, Fráncfort d.M. / Madrid.

(ed.), 1999, El debate de la poscolonialidad en Latinoamérica. Una posmodernidad periférica o cambio de paradigma en el pensamiento latinoamericano, Vervuert, Fráncfort d.M. / Madrid.

Vidal, Hernán, 1993, "The Concept of Colonial and Postcolonial Discourse: A Perspective from Literary Criticism" en Latin American Research Review, 28/3, pp. 113-119.

Young, Richard A. (ed.), 1997, Latin American Postmodernisms. Postmodern Studies, Richard A. Young, Ámsterdam / Atlanta. 